\title{
Neurodevelopmental outcome in hypoplastic left heart syndrome: Impact of perioperative cerebral tissue oxygenation of the Norwood procedure
}

Jan H. Hansen, MD, ${ }^{\mathrm{a}}$ Ina Rotermann, PsyM, ${ }^{\mathrm{a}}$ Jana Logoteta, MD, ${ }^{\mathrm{a}}$ Olaf Jung, MD, ${ }^{\mathrm{a}}$ Peter Dütschke, MD, Jens Scheewe, $\mathrm{MD},{ }^{\mathrm{c}}$ and Hans-Heiner Kramer, $\mathrm{MD}, \mathrm{PhD}^{\mathrm{a}}$

\section{ABSTRACT}

Objectives: Patients with hypoplastic left heart syndrome are at risk for neurodevelopmental impairment. Hypoxic-ischemic brain injury during neonatal treatment might be a relevant cause. We evaluated the association between cerebral oxygenation in the perioperative course of the Norwood procedure and neurodevelopmental outcome.

Methods: Cerebral tissue oxygen saturation $\left(\mathrm{ScO}_{2}\right)$ was obtained by near-infrared spectroscopy for 24 hours before and 48 hours after surgery in 43 patients. Full-scale, verbal, and performance IQ scores were evaluated with the Wechsler Preschool and Primary Scale of Intelligence at a median of 4.5 years (range, 3.5-6.8 years). Cognitive functions were assessed with the German Kognitiver Entwicklungstest für das Kindergartenalter (KET-KID).

Results: Mean IQ scores and KET-KID percentile ranks were in the lower-normal range (full-scale IQ, $94 \pm 11$; verbal IQ, $97 \pm 13$; performance IQ, $93 \pm 9$; KETKID global, $42 \pm 27$; verbal, $48 \pm 29$; nonverbal, $37 \pm 23)$. Scores were below average (full scale IQ $<85$ or KET-KID $<16$ th percentile) in 12 cases. Mean preoperative $\mathrm{ScO}_{2}$ was lower in patients scoring below average $(56.8 \% \pm 7.1 \%$ vs $61.7 \% \pm 5.8 \% ; P=.028)$ and was correlated with full-scale IQ $(r=0.495$; $P=.001)$, verbal IQ $(r=0.524 ; P=.001)$, and performance IQ $(r=0.386$; $P=.012)$ scores, and with global $(r=0.360 ; P=.018)$ and verbal $(r=0.395$, $P=.009)$ KET-KID scores. A relationship between IQ or KET-KID scores and postoperative $\mathrm{ScO}_{2}$ was not found. Gestational age, head circumference $z$-score, age at surgery, and postoperative length of stay were associated with IQ and KET-KID scores.

Conclusions: Neurodevelopmental outcome was in the lower-normal range. Along with innate patient factors, preoperative cerebral tissue oxygenation is likely an important determinant of cognitive development. (J Thorac Cardiovasc Surg 2016;151:1358-66)

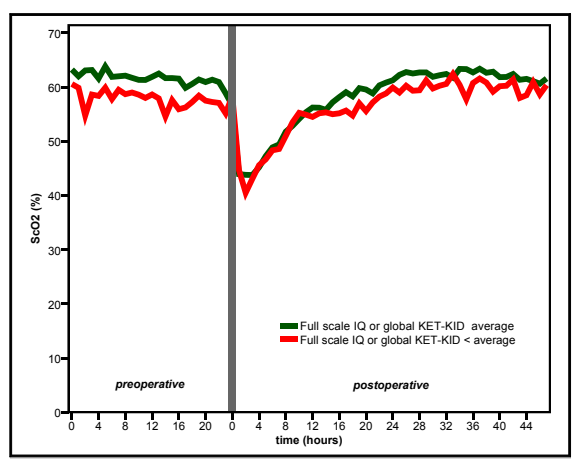

Perioperative cerebral tissue oxygenation compared with neurodevelopmental outcome.

\section{Central Message}

Preoperative cerebral tissue oxygenation is related to neurodevelopmental outcome in children undergoing the Norwood procedure.

\section{Perspective}

Hypoxic-ischemic brain injury might impair neurodevelopmental outcome in children undergoing the Norwood procedure. Decreased postoperative cerebral tissue oxygenation has been attributed to cognitive impairment. In contrast, only preoperative cerebral tissue oxygenation was related to neurodevelopmental outcome in our study. The impact of preoperative cerebral oxygenation warrants further investigation.

See Editorial Commentary page 1367.
Surgical and perioperative management of patients with hypoplastic left heart syndrome (HLHS) have steadily improved, resulting in substantially increased survival.

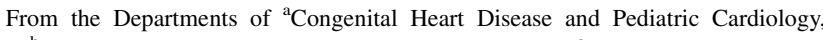
${ }^{\mathrm{b}}$ Anesthesiology and Intensive Care Medicine, and ${ }^{\mathrm{c}}$ Cardiovascular Surgery, University Hospital Schleswig-Holstein, Kiel, Germany.

Received for publication Nov 11, 2015; revisions received Jan 8, 2016; accepted for publication Feb 7, 2016.

Address for reprints: Jan H. Hansen, MD, Department of Congenital Heart Disease and Pediatric Cardiology, University Hospital of Schleswig Holstein, Campus Kiel, Arnold-Heller Strasse 3, House 9, 24105 Kiel, Germany (E-mail: jan. hansen@uk-sh.de).

0022-5223/\$36.00

Copyright (c) 2016 by The American Association for Thoracic Surgery

http://dx.doi.org/10.1016/j.jtcvs.2016.02.035
}

Nonetheless, neurodevelopmental problems, including cognitive impairment, fine and gross motor deficits, and speech and language disorders, are common in children with HLHS. ${ }^{1-6}$ Therefore, identification of risk factors is of great interest for improving long-term neurodevelopmental outcomes. Near-infrared spectroscopy (NIRS) allows noninvasive and real-time measurement of cerebral

Scanning this QR code will take you to the article title page.

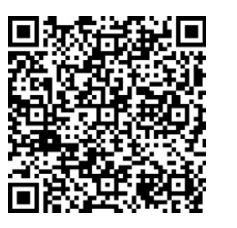




\begin{tabular}{|c|c|}
\hline \multicolumn{2}{|c|}{ Abbreviations and Acronyms } \\
\hline AUC & $=$ area under the curve \\
\hline HAWIVA- & $\begin{aligned} {[=} & \text { Hannover-Wechsler Intelligence } \\
& \text { Scale, Third Edition }\end{aligned}$ \\
\hline HLHS & $=$ Hypoplastic left heart syndrome \\
\hline KET-KID & $\begin{aligned}= & \text { Kognitiver Entwicklungstest für das } \\
& \text { Kindergartenalter }\end{aligned}$ \\
\hline NIRS & $=$ near-infrared spectroscopy \\
\hline $\mathrm{ScO}_{2}$ & $=$ cerebral tissue oxygen saturation \\
\hline $\mathrm{SsO}_{2}$ & $=$ somatic tissue oxygen saturation \\
\hline SCPA & $\begin{aligned}= & \text { superior cavopulmonary } \\
& \text { anastomosis }\end{aligned}$ \\
\hline TCPC & $=$ total cavopulmonary connection \\
\hline
\end{tabular}

tissue oxygen saturation $\left(\mathrm{ScO}_{2}\right)$ and is being increasingly used for perioperative monitoring of patients with congenital heart disease. ${ }^{7}$

Patients undergoing the Norwood procedure may be at risk for hypoxic-ischemic brain injury, with decreasing $\mathrm{ScO}_{2}$ observed in the early postoperative course. ${ }^{8-10}$ Previous studies have reported abnormal findings on magnetic resonance imaging and worse neurodevelopmental outcomes. ${ }^{11,12}$

The purpose of this study was to assess the association between perioperative $\mathrm{ScO}_{2}$ and neurodevelopmental outcomes in survivors of staged palliation for HLHS. In addition, potential risk factors for impaired neurodevelopmental outcome, including innate factors and variables related to surgical palliation, were evaluated.

\section{METHODS \\ Patient Population}

Children age 3.5 to 7 years who underwent staged palliation for HLHS or similar lesions were eligible to participate in this study. A total of 86 patients underwent the Norwood procedure between September 2006 and December 2010. Of these, 71 survived until Fontan surgery. Late death occurred in 2 cases. In addition, 7 patients with incomplete NIRS data and 2 non-German-speaking children were excluded. In 17 patients, testing was still pending or the parents denied participation. The remaining 43 patients were included in the analysis. Patients with genetic anomalies were not enrolled. Patient characteristics and surgical data were obtained from an institutional research database. Head circumference $z$-scores at birth were calculated adjusted for gender and gestational age based on reference data presented by Voigt et al. ${ }^{13}$ Microcephaly was defined as head circumference $z$-score of -2 or less.

\section{Perioperative Management}

In the preoperative period, all patients were treated according to a standardized protocol consisting of afterload reduction with sodiumnitroprusside or phentolamine, low-dose prostaglandin E1, furosemide, enteral feeding, and avoidance of mechanical ventilation or inotropic support. ${ }^{14}$

In the postoperative period, systemic afterload reduction therapy with sodium nitroprusside or with the alpha-blocker phentolamine was provided in all patients. In addition, patients received the phosphodiesterase-III inhibitor enoximone or milrinone. Inotropic support was achieved with epinephrine. Analgesia and sedation were controlled with morphine.

NIRS was part of the perioperative routine monitoring. Institutional protocols in terms of a goal-directed therapy did not exist, however. Preoperative and postoperative therapy and interventions were guided primarily by arterial oxygen saturation, arterial $\mathrm{pO}_{2}$ and $\mathrm{pCO}_{2}$ levels, acid-base status, arterial blood pressure, central venous saturations, and echocardiographic right ventricular function. Transfusion of red blood cells was provided to keep hemoglobin levels $>14 \mathrm{~g} / \mathrm{dL}$.

\section{Data Collection}

Routine perioperative monitoring included continuous measurement of arterial oxygen saturation $\left(\mathrm{SaO}_{2}\right)$, invasive arterial blood pressure and central venous pressure in the superior vena cava. Hemodynamic monitoring was performed using the IntelliVue system (Philips Healthcare, Best, The Netherlands). Arterial blood gas measurements were obtained at 1- to 2-hour intervals. Central venous blood gases were sampled from the superior vena cava and analyzed at 4-hour intervals for the first 48 postoperative hours.

NIRS probes were placed on the patient's midline forehead and slightly to the right of midline on the T10-L2 posterior flank. Cerebral oxygen saturation $\left(\mathrm{ScO}_{2}\right)$ and somatic tissue oxygen saturation $\left(\mathrm{SsO}_{2}\right)$ data were stored digitally with the INVOS 5100 system (Covidien, Mansfield, Mass) and were matched to the hemodynamic and respiratory data for 24 hours preoperatively and for 48 hours postoperatively. Mean values for hemodynamic, respiratory, and NIRS data were calculated for the last 24 preoperative hours (baseline), for the first 4 postoperative hours (early postoperative course), and the entire 48 -hour postoperative period. A cutoff value of $40 \%$ was chosen to define periods of diminished $\mathrm{ScO}_{2}$. The absolute duration of $\mathrm{ScO}_{2}<40 \%$ was evaluated. The area under the curve (AUC) of $\mathrm{ScO}_{2}<40 \%$ was calculated to indicate the extent of desaturation below the threshold of $40 \%$, using the following equation: $\mathrm{AUC}=\mathrm{ScO}_{2}$ $<40 \% \times$ duration in minutes. To estimate cerebral oxygen extraction, the difference between $\mathrm{SaO}_{2}$ and $\mathrm{ScO}_{2}$ was calculated for the preoperative and postoperative measurements $\left(\Delta \mathrm{SacO}_{2}=\mathrm{SaO}_{2}-\mathrm{ScO}_{2}\right)$.

\section{Norwood Procedure}

Surgical technique has been described in detail previously. ${ }^{15}$ Pulmonary blood flow was established using a modified Blalock-Taussig shunt. Surgery was performed with deep hypothermia and selective antegrade cerebral perfusion via the modified Blalock-Taussig shunt during aortic arch reconstruction with a pump flow of approximately $15 \%$ of the target total bypass flow. The ph-stat method was used for cooling to a minimum temperature of $18^{\circ} \mathrm{C}$, and was continued during bypass and antegrade cerebral perfusion. Patients were rewarmed with the alpha-stat method. Hemofiltration was routinely used before weaning from bypass. Primary chest closure was attempted in all patients.

\section{Subsequent Procedures}

Subsequent procedures included a superior cavopulmonary anastomosis (SCPA) using the hemi-Fontan technique, followed by a total cavopulmonary connection (TCPC) with a fenestrated intra-atrial tunnel. Data on age and weight at surgery and duration of cardiopulmonary support were collected. As a rough measure for complexity of the entire surgical palliation, cumulative cardiopulmonary bypass times and cumulative length of hospital stay were calculated for all 3 surgical procedures.

\section{Assessment of Neurodevelopmental Outcomes}

Two different tests were administered and analyzed by a single psychologist. Verbal IQ, performance IQ, and full-scale IQ were 
TABLE 1. Patient characteristics and surgical data

\begin{tabular}{|c|c|c|c|}
\hline & Enrolled $(n=43)$ & Not enrolled $(n=28)$ & $P$ value \\
\hline Sex, male/female, $\mathrm{n}$ & $28 / 15$ & $21 / 7$ & .439 \\
\hline Prenatal diagnosis, $\mathrm{n}(\%)$ & $35(81.4)$ & $22(78.6)$ & .770 \\
\hline Anatomy, n (\%) & & & .688 \\
\hline MA/AA & $16(37.2)$ & $10(35.7)$ & \\
\hline MS/AS & $10(23.3)$ & $4(14.3)$ & \\
\hline MS/AA & $10(23.3)$ & $7(25.0)$ & \\
\hline MA/AS & $3(7.0)$ & $1(3.6)$ & \\
\hline non-HLHS & $4(9.3)$ & $6(21.6)$ & \\
\hline Diameter ascending aorta $(\mathrm{mm})$ & $3.8 \pm 1.6$ & $3.6 \pm 1.7$ & .494 \\
\hline Gestational age, wk, median (range) & $40(35-42)$ & $40(36-41)$ & .543 \\
\hline Weight at birth, $\mathrm{kg}$, mean $\pm \mathrm{SD}$ & $3.34 \pm 0.49$ & $3.20 \pm 0.49$ & .249 \\
\hline Length at birth, $\mathrm{cm}$, mean $\pm \mathrm{SD}$ & $50.9 \pm 2.6$ & $50.4 \pm 2.6$ & .427 \\
\hline Head circumference at birth $z$-score, mean \pm SD & $-0.76 \pm 1.05$ & $-0.78 \pm 1.03$ & .928 \\
\hline Microcephaly, n (\%) & $6(14.0)$ & $3(10.7)$ & .735 \\
\hline \multicolumn{4}{|l|}{ Norwood procedure } \\
\hline Age at surgery, d, median (range) & $5(2-30)$ & $5(3-125)$ & .161 \\
\hline Weight at surgery, $\mathrm{kg}$, mean $\pm \mathrm{SD}$ & $3.33 \pm 0.46$ & $3.34 \pm 0.47$ & .981 \\
\hline Cardiopulmonary bypass, min, mean \pm SD & $144 \pm 21$ & $161 \pm 43$ & .061 \\
\hline Selective cerebral perfusion, min, mean $\pm \mathrm{SD}$ & $45 \pm 16$ & $49 \pm 19$ & .410 \\
\hline Postoperative ventilation, $\mathrm{h}$, median (range) & $59(30-120)$ & $67(43-403)$ & .012 \\
\hline Inotropic support, h, median (range) & $38(13-104)$ & $46(12-575)$ & .211 \\
\hline Afterload reduction, $\mathrm{h}$, median (range) & $73(28-482)$ & 93 (39-696) & .036 \\
\hline Postoperative stay, d, median (range) & $45(23-93)$ & $47(22-126)$ & .984 \\
\hline \multicolumn{4}{|l|}{ Superior cavopulmonary anastomosis } \\
\hline Median age at surgery, mo, median (range) & $3.2(1.2-10.0)$ & $3.6(1.1-10)$ & .388 \\
\hline Transcutaneous oxygen saturation, $\%$, mean $\pm \mathrm{SD}$ & $79 \pm 5$ & $79 \pm 5$ & .700 \\
\hline Weight at surgery, $\mathrm{kg}$, mean $\pm \mathrm{SD}$ & $5.22 \pm 0.79$ & $5.39 \pm 0.85$ & .380 \\
\hline Postoperative stay, $\mathrm{d}$, median (range) & $17(9-57)$ & $15(7-83)$ & .596 \\
\hline \multicolumn{4}{|l|}{ Total cavopulmonary anastomosis } \\
\hline Median age at surgery, $y$, median (range) & $2.7(1.8-5.1)$ & $2.7(2.0-5.0)$ & .741 \\
\hline Transcutaneous oxygen saturation, $\%$, mean $\pm \mathrm{SD}$ & $82 \pm 4$ & $84 \pm 3$ & .145 \\
\hline Weight at surgery, $\mathrm{kg}$, mean $\pm \mathrm{SD}$ & $12.6 \pm 1.57$ & $12.5 \pm 1.4$ & .607 \\
\hline Postoperative stay, $\mathrm{d}$, median (range) & $12(6-25)$ & $11(6-35)$ & 657 \\
\hline
\end{tabular}

Significant difference are in bold type. $M A$, Mitral atresia; $A A$, aortic atresia; $M S$, mitral stenosis; $A S$, aortic stenosis; $H L H S$, hypoplastic left heart syndrome; $S D$, standard deviation.

evaluated with the Hannover-Wechsler Intelligence Scale, Third Edition (HAWIVA-III; the German version of the Wechsler Preschool and Primary Scale of Intelligence, Third Edition). Processing speed was assessed with the Coding and Symbol Search subtest. IQ scores of 85 to 115 points and above were classified as "average" and "above average," respectively. Results of $<85$ points ( $<1 \mathrm{SD}$ ) were classified as "below average."

Cognitive functions were assessed with the Kognitiver Entwicklungstest für das Kindergartenalter (KET-KID; in English, Cognitive Development Test for Preschool-Age Children), a German test to assess cognitive development in preschool-age children. The KET-KID is composed of 8 subtests, evaluating visual perceptual skills, auditory and visual memory, expressive and receptive communication skills, attention, and psychomotor development. Results are summarized on a global scale for cognitive development and on verbal and nonverbal scales. Scores are presented as percentile ranks. Results between the 16th and 84th percentile and above were classified as average and above average, respectively. Results below the 16th percentile are indicative of developmental delay and were classified as below average.

Patients were divided into 2 groups based on their performance on the 2 tests. Patients with below-average full-scale IQ or global KET-KID scores were compared with those with average or above average scores on the 2 tests.

Patient family socioeconomic status was evaluated using a questionnaire to develop an index composed of parents' education, occupational status, and income. Based on this index, social stratum was divided into 3 different classes (upper, middle, and lower).

\section{Statistical Analysis}

Continuous variables are expressed as mean and standard deviation or median and range as appropriate; categorical data, as count and percentages. Fisher's exact test was used to analyze categorical data. Continuous variables were compared with the Student $t$ test for 1 sample or 2 independent samples, or with the Mann-Whitney $U$ test for non-normally distributed data. Correlations were calculated using the Pearson correlation coefficient. The relationships among neurodevelopmental test scores, NIRS data, patient characteristics, and surgical variables were evaluated with stepwise linear regression analysis. Potential risk factors for impaired neurodevelopmental outcome were evaluated by univariate analysis. Statistical analyses were performed with SPSS 22.0 
(IBM, Armonk, NY). A $P$ value $<.05$ was considered statistically significant.

Local Research Ethics Committee approval was obtained for neurodevelopmental assessment and analysis of clinical data related to staged surgical palliation.

\section{RESULTS}

Patient characteristics and surgical data for the 3 surgical steps for the 43 patients enrolled in the study and the 28 patients who survived Fontan completion but did not undergo neurodevelopmental assessment are compared in Table 1. Except for duration of postoperative mechanical ventilation and duration of afterload reduction therapy after the Norwood procedure, no differences were found.

Among the 4 patients without HLHS enrolled in the study, the underlying anatomy was unbalanced atrioventricular septal defect, double-outlet right ventricle, mitral atresia, and congenitally corrected transposition of the great arteries in 1 patient each. No patient had a noncardiac anomaly. Prematurity was present in 4 cases. Head circumference $\mathrm{z}$-scores at birth were significantly lower compared with population norms $(P<.001)$; microcephaly was present in 6 patients $(14 \%)$. The median age at the Norwood procedure was 5 days. Six patients underwent surgery beyond the first week of life. In 1 patient, surgery was electively scheduled for the eighth day of life. In 3 patients, clinical stabilization after circulatory collapse was warranted. In 1 premature neonate, a bilateral pulmonary artery band was placed before or to the Norwood procedure. One child with borderline left heart dimensions first underwent an attempted biventricular repair. In the last 2 patients, Norwood surgery was performed at age 30 and 28 days, respectively.

Superior cavopulmonary anastomosis (SCPA) was performed at a median age of 3.2 months and total cavopulmonary connection (TCPC) completed staged surgical palliation at a median age of 2.7 years.

\section{Regional Tissue Oxygenation}

Figure 1 shows perioperative cerebral and somatic tissue oxygen saturations. Mean preoperative $\mathrm{ScO}_{2}$ and $\mathrm{SsO}_{2}$ values were in the same range $(60.3 \% \pm 6.5 \%$ and $58.9 \% \pm 7.3 \%$, respectively). $\mathrm{ScO}_{2}$ values declined during the early postoperative course, reaching a nadir after approximately 2 hours. Early postoperative $\mathrm{ScO}_{2}$ was significantly lower compared to preoperative baseline $(43.8 \% \pm 8.3 \%$ vs $60.3 \% \pm 6.5 \% ; P<.001)$. Somatic saturation values were higher than cerebral saturation values and showed a slight decline during the first 48 postoperative hours. $\mathrm{ScO}_{2}$ was $<40 \%$ for a median duration of 88 minutes (range, 0-429 minutes). The median AUC of $\mathrm{ScO}_{2}<40 \%$ was $368 \mathrm{~min} \%$ (range, $0-3405 \min \%$ ). The arterial-cerebral oxygen saturation difference was

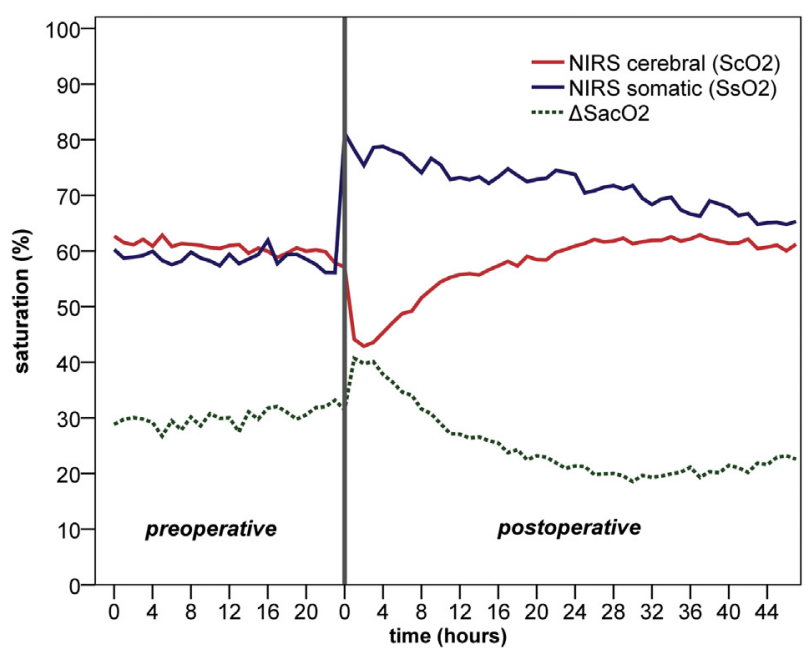

FIGURE 1. Preoperative and postoperative $\mathrm{ScO}_{2}$ (red) and $\mathrm{SsO}_{2}$ (blue) derived by NIRS. The arterial and cerebral oxygen saturation difference $\left(\triangle \mathrm{SacO}_{2}=\mathrm{SaO}_{2}-\mathrm{ScO}_{2}\right.$ ) estimates cerebral oxygen extraction (green). $\mathrm{ScO}_{2}$, Cerebral tissue oxygen saturation; $\mathrm{SsO}_{2}$, somatic tissue oxygen saturation.

increased in the early postoperative period compared with the preoperative baseline value $(39.3 \% \pm 8.6 \%$ vs $30.8 \% \pm 5.1 \% ; P<.001)$. In the longer postoperative course, $\Delta \mathrm{SacO}_{2}$ decreased and was $25.2 \% \pm 5.3 \%$ for the entire 48-hour period, significantly lower compared with the preoperative period $(P<.001)$.

\section{Neurodevelopmental Outcomes}

Neurodevelopmental outcomes were assessed at a median age of 4.5 years (range, 3.5-6.8 years) (Table 2). Overall, IQ and KET-KID scores were in the normal range; however, full-scale IQ, performance IQ, and global and nonverbal KET-KID scores were significantly lower than population norms $(P<.001)$. Full-scale IQ was below average in 8 patients $(19 \%)$, and global developmental delay was seen in 11 patients $(25.6 \%)$. Overall, 12 patients $(27.9 \%)$ had a below-average full-scale IQ or global KET-KID score. Developmental delay in at least 1 domain was found in 27 patients $(62.8 \%)$. Seventeen patients $(39.5 \%)$ had a belowaverage score in 2 or more domains. The most frequently affected domains were psychomotor development, visuoconstructive skills and visual memory as well as articulation and verbal memory.

Associations among test scores and $\mathrm{ScO}_{2}$ and derived parameters were evaluated by correlation analysis and linear regression analysis (Table 3). Full-scale and verbal IQ were moderately correlated with preoperative $\mathrm{ScO}_{2}$. A similar relationship was found between nonverbal IQ and preoperative $\mathrm{ScO}_{2}$, as well as between global and verbal KET-KID results and preoperative $\mathrm{ScO}_{2}$. There was no association between postoperative 
TABLE 2. Neurocognitive test results

\begin{tabular}{|c|c|c|}
\hline $\begin{array}{c}\text { HAWIVA-III } \\
\text { (normal range, } 85-115)(n=42)\end{array}$ & $\begin{array}{r}\text { Test score, } \\
\text { mean } \pm \text { SD }\end{array}$ & Score $<\mathbf{8 5}$, n (\%) \\
\hline Full-scale IQ & $94 \pm 11$ & $8(19.0)$ \\
\hline Verbal IQ & $97 \pm 13$ & $6(14.3)$ \\
\hline Nonverbal IQ & $93 \pm 9$ & $7(16.7)$ \\
\hline Processing speed & $95 \pm 11$ & $6(14.3)$ \\
\hline $\begin{array}{l}\text { KET-KID (normal range, 16-84) } \\
\qquad(n=43)\end{array}$ & $\begin{array}{l}\text { Test score, } \\
\text { mean } \pm \text { SD }\end{array}$ & Score $<\mathbf{P 1 6}, \mathbf{n}(\%)$ \\
\hline Global KET-KID & $42 \pm 27$ & $11(25.6)$ \\
\hline Verbal KET-KID & $48 \pm 29$ & $9(20.9)$ \\
\hline Nonverbal KET-KID & $37 \pm 23$ & $8(18.6)$ \\
\hline Psychomotor development & $35 \pm 26$ & $13(30.2)$ \\
\hline Articulation & $50 \pm 29$ & $8(18.6)$ \\
\hline Verbal memory & $46 \pm 28$ & $9(20.9)$ \\
\hline Verbal comprehension & $50 \pm 26$ & $4(9.3)$ \\
\hline Visual perception & $52 \pm 24$ & $1(2.3)$ \\
\hline Visuoconstruction & $31 \pm 23$ & $14(32.6)$ \\
\hline Visual memory & $41 \pm 30$ & $11(25.6)$ \\
\hline
\end{tabular}

HAWIVA-III, Hannover-Wechsler Intelligence Scale, Third Edition; SD, standard deviation; KET-KID, Kognitiver Entwicklungstest für das Kindergartenalter.

NIRS measurements and neurodevelopmental outcomes. Significant correlations with IQ or KET-KID score were found for gestational age, head circumference $z$-score, age at surgery, and postoperative length of stay. In stepwise linear regression analysis, head circumference $z$-score, gestational age, length of postoperative stay, and preoperative $\mathrm{ScO}_{2}$ were significantly related to full-scale IQ $\left(R^{2}=0.559\right)$. Global KET-KID score was predicted by a model including the variables head circumference $z$-score, age at surgery, and postoperative length of stay $\left(R^{2}=0.392\right)$.

\section{Risk Factor Analysis for Impaired Neurodevelopmental Outcome}

As shown in Figure 2, preoperative cerebral NIRS values were significantly lower in patients with below-average test scores, whereas early postoperative values and mean $\mathrm{ScO}_{2}$ for the entire 48-hour postoperative period were not significantly different (Table 4). The postoperative duration of $\mathrm{ScO}_{2}$ values $<40 \%$ (median, 81 minutes [range, 0-422 minutes] vs 88 minutes [range, 0-429 minutes]; $P=.862$ ) and AUC $<40 \%$ (median, $260 \mathrm{~min} \%$ [range, 0-2698 $\mathrm{min} \%$ ] vs $368 \mathrm{~min} \%$ [range, 0-3405 $\mathrm{min} \%$ ]; $P=.718$ ) were not different between patients with below-average scores and those with normal test results.

Table 4 displays routine intensive care monitoring data, including heart rate, invasive mean arterial blood pressure values, and blood gas analysis results for the preoperative period, the early postoperative period, and the entire postoperative period. Except for a higher heart rate and lower arterial oxygen saturation values in the preoperative course in patients with belowaverage test scores, no between-group differences were found.

Table 5 compares patient-related variables and potential risk factors related to surgical palliation between patients with below-average test results and patients with average or above-average results. Gestational age was younger and birth weight tended to be lower in the patients with below-average scores. Head circumference $z$-score was significantly lower and microcephaly was more common in the patients with below-average scores.

Among variables related to surgical palliation, age at the time of the Norwood procedure tended to be higher in the patients with full-scale IQ below population norms or global developmental delay. Age at surgery was negatively

TABLE 3. Correlation analysis

\begin{tabular}{|c|c|c|c|c|c|c|c|c|c|c|c|c|}
\hline \multirow[b]{3}{*}{ Variable } & \multicolumn{6}{|c|}{ HAWIVA-III } & \multicolumn{6}{|c|}{ KET-KID } \\
\hline & \multicolumn{2}{|c|}{ Full-scale } & \multicolumn{2}{|c|}{ Verbal } & \multicolumn{2}{|c|}{ Nonverbal } & \multicolumn{2}{|c|}{ Global } & \multicolumn{2}{|c|}{ Verbal } & \multicolumn{2}{|c|}{ Nonverbal } \\
\hline & $r$ & $P$ & $r$ & $P$ & $r$ & $P$ & $r$ & $P$ & $r$ & $P$ & $r$ & $P$ \\
\hline \multicolumn{13}{|l|}{ Cerebral oxygenation } \\
\hline $\mathrm{ScO}_{2}$ baseline & 0.495 & .001 & 0.524 & $<.001$ & 0.386 & .012 & 0.360 & .018 & 0.395 & .009 & 0.223 & .150 \\
\hline $\mathrm{ScO}_{2}$ at $0-4 \mathrm{~h}$ postsurgery & 0.054 & .732 & 0.013 & .937 & 0.068 & .670 & 0.083 & .598 & 0.051 & .746 & 0.074 & .639 \\
\hline $\mathrm{ScO}_{2}$ at $0-48 \mathrm{~h}$ postsurgery & 0.136 & .392 & 0.107 & .500 & 0.152 & .337 & 0.085 & .587 & 0.080 & .609 & 0.019 & .905 \\
\hline Duration of $\mathrm{ScO}_{2}<40 \%$ & 0.051 & .751 & 0.114 & .473 & -0.021 & .895 & 0.014 & .927 & 0.100 & .523 & -0.058 & .713 \\
\hline AUC of $\mathrm{ScO}_{2}<40 \%$ & 0.075 & .635 & 0.129 & .416 & -0.029 & .856 & 0.059 & .708 & 0.138 & .377 & -0.028 & .861 \\
\hline \multicolumn{13}{|c|}{ Innate patient factors and variables related to Norwood surgery } \\
\hline Gestational age & 0.311 & .045 & 0.234 & .136 & 0.225 & .152 & 0.280 & .069 & 0.283 & .066 & 0.224 & .148 \\
\hline Birth weight & 0.346 & .025 & 0.111 & .486 & 0.509 & $<.001$ & 0.234 & .131 & 0.113 & .472 & 0.247 & .111 \\
\hline Head circumference $z$-score & 0.556 & $<.001$ & 0.441 & .004 & 0.519 & $<.001$ & 0.424 & .005 & 0.347 & .023 & 0.392 & .009 \\
\hline Age at surgery & -0.439 & .004 & -0.421 & .005 & -0.437 & .004 & -0.307 & .045 & -0.329 & .031 & -0.192 & .218 \\
\hline Postoperative length of stay & -0.411 & .007 & -0.422 & .005 & -0.364 & .018 & -0.389 & .010 & -0.429 & .004 & -0.233 & .132 \\
\hline
\end{tabular}

Significant correlations are in bold type. HAWIVA-III, Hannover-Wechsler Intelligence Scale, Third Edition; KET-KID, Kognitiver Entwicklungstest für das Kindergartenalter; $\mathrm{ScO}_{2}$, cerebral tissue oxygen saturation; $A U C$, area under the curve. 


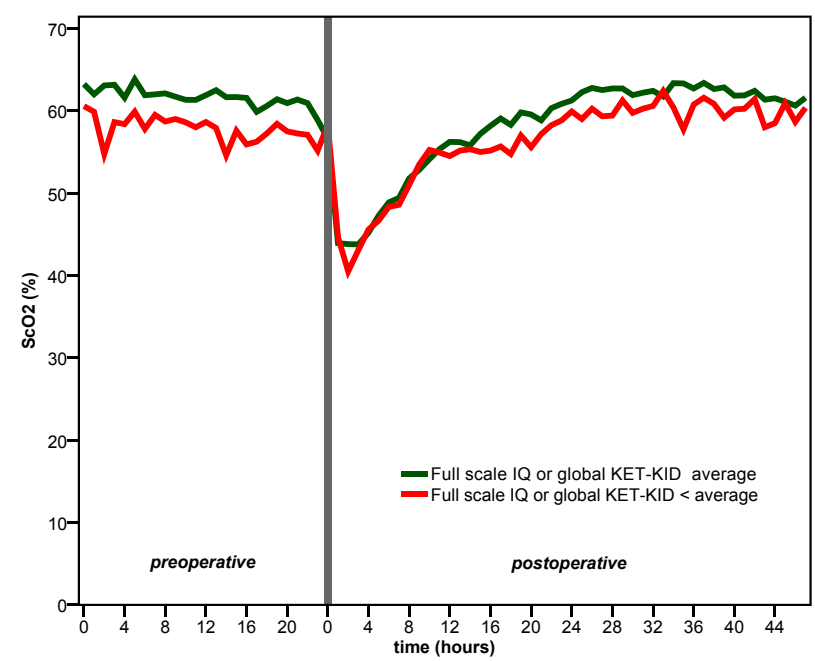

FIGURE 2. Preoperative and postoperative $\mathrm{ScO}_{2}$ derived by NIRS in patients with average or above-average full-scale IQ and KET-KID scores (green) compared with patients with a below-average full-scale IQ or KET-KID score. $\mathrm{ScO}_{2}$, Cerebral tissue oxygen saturation; KET-KID, Kognitiver Entwicklungstest für das Kindergartenalter.

correlated with preoperative $\mathrm{ScO}_{2}(r=-0.54 ; P<.001)$. Cardiopulmonary bypass time, duration of postoperative ventilation, inotropic support, afterload reduction therapy, and postoperative length of stay were not different between groups. Age and weight at subsequent surgical procedures showed no difference between patients with belowaverage test scores and with those with average or aboveaverage scores. As a rough measure of the complexity of the entire surgical palliation, cumulative length of hospital stay tended to be longer in the patients with below-average full-scale IQ or global KET-KID scores (Table 5).

\section{DISCUSSION}

Neonates with HLHS are at risk for low $\mathrm{ScO}_{2}$, and hypoxic-ischemic brain injury may be an important determinant of cognitive impairment. In our cohort of patients with HLHS, neurodevelopmental outcomes at preschool age was in the lower-normal range; however, developmental problems were common. Global developmental delay was seen in $26 \%$ of our patients, and impairment in at least 1 neuropsychological domain was found in $63 \%$. A relationship between low postoperative $\mathrm{ScO}_{2}$ after the Norwood procedure and neurodevelopmental outcome was not be demonstrated. In contrast, preoperative $\mathrm{ScO}_{2}$ was significantly related to IQ and KET-KID scores. In addition, innate patient factors, including smaller head circumference $z$ score, microcephaly, and lower gestational age, were identified as potential risk factors for impaired neurodevelopmental outcome. Among the variables related to the Norwood procedure, older age at surgery and longer postoperative stay were associated with lower IQ and KETKID scores.

Neurodevelopmental outcomes in preschool or school-age patients with HLHS has been assessed in previous studies; however, their comparability is limited..$^{3-}$

${ }^{6}$ Ages at evaluation and neurocognitive tests applied varied among these studies. Patient cohorts were relatively small, resulting in insufficient statistical power. The neurodevelopmental profile of our cohort is comparable to that of the cohort studied by Brosig and colleagues, ${ }^{6}$ who evaluated neurodevelopmental outcomes

TABLE 4. Regional tissue oxygen saturation monitoring and routine intensive care data

\begin{tabular}{|c|c|c|c|c|c|c|c|c|c|}
\hline & \multicolumn{3}{|c|}{$\begin{array}{l}\text { Preoperative baseline } \\
\text { IQ or KET-KID score }\end{array}$} & \multicolumn{3}{|c|}{$\begin{array}{l}\text { Early postoperative }(0-4 \text { h) } \\
\text { IQ or KET-KID score }\end{array}$} & \multicolumn{3}{|c|}{$\begin{array}{l}\text { Postoperative (0-48 h) } \\
\text { IQ or KET-KID score }\end{array}$} \\
\hline & $\begin{array}{c}<\text { Norm } \\
(\mathbf{n}=12)\end{array}$ & $\begin{array}{l}\geq \text { Norm } \\
(\mathbf{n}=31)\end{array}$ & $\begin{array}{c}P \\
\text { value }\end{array}$ & $\begin{array}{l}<\text { Norm } \\
(\mathrm{n}=12)\end{array}$ & $\begin{array}{l}\geq \text { Norm } \\
(\mathbf{n}=\mathbf{3 1})\end{array}$ & $\begin{array}{c}P \\
\text { value }\end{array}$ & $\begin{array}{c}<\text { Norm } \\
(\mathbf{n}=12)\end{array}$ & $\begin{array}{l}\geq \text { Norm } \\
(\mathbf{n}=\mathbf{3 1})\end{array}$ & $\begin{array}{c}P \\
\text { value }\end{array}$ \\
\hline $\mathrm{ScO}_{2}, \%$ & $56.8 \pm 7.1$ & $61.7 \pm 5.8$ & .028 & $42.6 \pm 8.1$ & $44.3 \pm 8.5$ & .536 & $56.0 \pm 2.8$ & $58.4 \pm 5.6$ & .070 \\
\hline$\Delta \mathrm{SacO}_{2}, \%$ & $31.5 \pm 3.4$ & $30.5 \pm 5.6$ & .474 & $38.8 \pm 8.3$ & $39.5 \pm 8.8$ & .803 & $26.2 \pm 3.5$ & $24.8 \pm 5.9$ & .441 \\
\hline $\mathrm{SsO}_{2}, \%$ & $57.3 \pm 7.6$ & $59.5 \pm 7.3$ & .383 & $74.1 \pm 8.9$ & $79.1 \pm 9.0$ & .105 & $67.9 \pm 5.6$ & $73.2 \pm 6.2$ & .103 \\
\hline Heart rate, beats/min & $157 \pm 9$ & $150 \pm 9$ & .028 & $160 \pm 10$ & $155 \pm 12$ & .219 & $154 \pm 8$ & $156 \pm 8$ & .671 \\
\hline MAP, mm Hg & $48.8 \pm 2.3$ & $49.6 \pm 5.2$ & .502 & $55.8 \pm 7.5$ & $55.4 \pm 5.8$ & .858 & $52.8 \pm 2.8$ & $52.4 \pm 3.4$ & .751 \\
\hline $\mathrm{CVP}, \mathrm{mm} \mathrm{Hg}$ & NA & NA & NA & $8.9 \pm 2.4$ & $8.1 \pm 1.5$ & .298 & $9.4 \pm 1.5$ & $8.8 \pm 1.2$ & .245 \\
\hline $\mathrm{pH}$ & $7.43 \pm 0.03$ & $7.42 \pm 0.07$ & .624 & $7.38 \pm 0.03$ & $7.38 \pm 0.06$ & .899 & $7.43 \pm 0.04$ & $7.44 \pm 0.02$ & .709 \\
\hline Base excess & $3.7 \pm 2.2$ & $2.9 \pm 3.2$ & .441 & $-1.1 \pm 1.2$ & $-1.1 \pm 2.0$ & .981 & $3.3 \pm 1.5$ & $3.2 \pm 1.6$ & .853 \\
\hline $\mathrm{pCO}_{2}, \mathrm{~mm} \mathrm{Hg}$ & $43.9 \pm 5.2$ & $41.7 \pm 5.3$ & .235 & $41.4 \pm 4.1$ & $42.2 \pm 7.8$ & .725 & $42.2 \pm 3.5$ & $41.6 \pm 3.8$ & .636 \\
\hline $\mathrm{pO}_{2}, \mathrm{~mm} \mathrm{Hg}$ & $47.7 \pm 4.8$ & $53.4 \pm 11.4$ & .102 & $42.7 \pm 5.2$ & $44.5 \pm 5.5$ & .333 & $43.9 \pm 2.6$ & $44.5 \pm 2.7$ & .516 \\
\hline $\mathrm{SaO}_{2}, \%$ & $86.8 \pm 4.6$ & $90.5 \pm 3.9$ & .010 & $79.1 \pm 5.4$ & $81.9 \pm 3.3$ & .120 & $80.5 \pm 3.3$ & $81.6 \pm 2.1$ & .337 \\
\hline $\mathrm{SvO}_{2}, \%$ & NA & NA & NA & $67.3 \pm 7.9$ & $67.2 \pm 9.1$ & .972 & $62.4 \pm 7.0$ & $64.4 \pm 6.0$ & .357 \\
\hline Hemoglobin, g/dL & $14.4 \pm 1.1$ & $13.9 \pm 1.1$ & .156 & $15.7 \pm 1.7$ & $15.3 \pm 1.1$ & .300 & $15.2 \pm 0.8$ & $14.9 \pm 0.7$ & .230 \\
\hline
\end{tabular}

Significant results are in bold type. $\mathrm{KET}$-KID, Kognitiver Entwicklungstest für das Kindergartenalter; $\mathrm{ScO}_{2}$, cerebral tissue oxygen saturation; $\triangle \mathrm{SacO}$, arterial-cerebral oxygen saturation difference; $\mathrm{SsO}_{2}$, somatic (renal) tissue oxygen saturation; $M A P$, mean arterial blood pressure; $\mathrm{CVP}$, central venous pressure; $N A$, not applicable; $p C \mathrm{O}_{2}$, partial pressure of carbon dioxide; $\mathrm{pO}_{2}$, partial pressure of oxygen; $\mathrm{SaO}_{2}$, arterial oxygen saturation; $\mathrm{SvO}$, central venous saturation. 
TABLE 5. Univariate risk factor analysis for impaired neurodevelopmental outcome

\begin{tabular}{|c|c|c|c|}
\hline \multirow[b]{2}{*}{ Variable } & \multicolumn{3}{|c|}{ Full-scale IQ or KET-KID score } \\
\hline & $<$ Normal range $(\mathrm{n}=12)$ & $\geq$ Normal range $(\mathbf{n}=\mathbf{3 1})$ & $P$ value \\
\hline Sex, male/female, $\mathrm{n}$ & $9 / 3$ & $19 / 12$ & .492 \\
\hline Socioeconomic status, median (range) & $2(1-3)$ & $2(1-3)$ & .565 \\
\hline Prenatal diagnosis, $\mathrm{n}(\%)$ & $10(83.3)$ & $25(80.6)$ & 1.000 \\
\hline Anatomy, n (\%) & & & .911 \\
\hline MA/AA & $5(41.7)$ & $11(35.5)$ & \\
\hline MS/AS & $2(16.7)$ & $7(22.6)$ & \\
\hline MS/AA & $4(33.3)$ & $7(22.6)$ & \\
\hline MA/AS & $0(0.0)$ & $3(9.7)$ & \\
\hline non-HLHS & $1(8.3)$ & $3(9.7)$ & \\
\hline Diameter of ascending aorta, $\mathrm{mm}$, mean $\pm \mathrm{SD}$ & $3.5 \pm 1.6$ & $4.0 \pm 1.7$ & .448 \\
\hline Gestational age, wk, median (range) & $39(36-40)$ & $40(35-42)$ & .037 \\
\hline Birth weight, $\mathrm{kg}$, mean $\pm \mathrm{SD}$ & $3.13 \pm 0.61$ & $3.42 \pm 0.42$ & .081 \\
\hline Head circumference $z$-score, mean \pm SD & $-1.36 \pm 0.87$ & $-0.53 \pm 1.03$ & .018 \\
\hline Microcephaly, n (\%) & $4(33.3)$ & $2(6.5)$ & .042 \\
\hline \multicolumn{4}{|l|}{ Norwood procedure } \\
\hline Age at surgery, $d$, median (range) & $6(3-30)$ & $4(2-11)$ & .055 \\
\hline Weight at surgery, $\mathrm{kg}$, mean $\pm \mathrm{SD}$ & $3.22 \pm 0.54$ & $3.39 \pm 0.42$ & .292 \\
\hline Indexed shunt diameter, $\mathrm{mm} / \mathrm{kg}$, mean $\pm \mathrm{SD}$ & $2.97 \pm 0.97$ & $2.68 \pm 0.30$ & .150 \\
\hline Cardiopulmonary bypass, min, mean $\pm \mathrm{SD}$ & $137 \pm 16$ & $147 \pm 23$ & .186 \\
\hline Selective cerebral perfusion, min, mean $\pm \mathrm{SD}$ & $43 \pm 18$ & $46 \pm 14$ & .377 \\
\hline Postoperative ventilation, $\mathrm{h}$, median (range) & $60(40-106)$ & $59(30-120)$ & .530 \\
\hline Inotropic support, h, median (range) & $40(24-104)$ & $36(13-95)$ & .414 \\
\hline Afterload reduction, h, median (range) & $71(45-131)$ & $75(28-482)$ & .462 \\
\hline Postoperative stay, $\mathrm{d}$, median (range) & $54(25-92)$ & $43(23-82)$ & .149 \\
\hline \multicolumn{4}{|l|}{ Staged surgical palliation } \\
\hline Age at SCPA, mo, median (range) & $3.0(1.8-5.2)$ & $3.2(1.2-10.0)$ & .718 \\
\hline Weight at SCPA, $\mathrm{kg}$, mean $\pm \mathrm{SD}$ & $5.08 \pm 0.65$ & $5.27 \pm 0.84$ & .491 \\
\hline Age at TCPC, y, median (range) & $2.8(2.2-5.1)$ & $2.5(1.8-4.5)$ & .265 \\
\hline Weight at TCPC, $\mathrm{kg}$, mean \pm SD & $12.9 \pm 1.57$ & $12.5 \pm 1.6$ & .457 \\
\hline Cumulative cardiopulmonary bypass, min, mean $\pm \mathrm{SD}$ & $385 \pm 44$ & $373 \pm 36$ & .400 \\
\hline Cumulative stay, $\mathrm{d}$, median (range) & $96(56-153)$ & $71(46-128)$ & .086 \\
\hline
\end{tabular}

KET-KID, Kognitiver Entwicklungstest für das Kindergartenalter; $M A$, mitral atresia; $A A$, aortic atresia; $M S$, mitral stenosis; $A S$, aortic stenosis; $H L H S$, hypoplastic left heart syndrome; $S D$, standard deviation; $S C P A$, superior cavopulmonary anastomosis; $T C P C$, total cavopulmonary connection.

of preschool-age patients with HLHS. ${ }^{6}$ The impact of postoperative $\mathrm{ScO}_{2}$ on neurodevelopmental outcome was evaluated in 21 patients of the same cohort in another study. ${ }^{12}$ Three patients with low or abnormal scores on the VisualMotor Integration Test, which served as the primary study endpoint, were identified. These patients had significantly lower average $\mathrm{ScO}_{2}$ during the first 48 postoperative hours compared with patients with average or above-average scores. The postoperative hours spent with $\mathrm{ScO}_{2}$ values $<45 \%$ and $<55 \%$ were related to lower visual-motor integration and to a neurodevelopmental index score combining the results of other neuropsychological domains. ${ }^{12}$ Compared with that study, the absolute postoperative cerebral NIRS values, which were obtained with the same NIRS monitor, were lower in our patients. Early postoperative NIRS values declined compared with preoperative values and were $<40 \%$ for a median duration of approximately 90 minutes in our patients. But early postoperative cerebral NIRS values, time at an $\mathrm{ScO}_{2}$ value $<40 \%$, or AUC $<40 \%$ were not linked to IQ or KET-KID score. The associations of these parameters with brain injury, which has been demonstrated in animal experiments, ${ }^{16,17}$ might be different in neonates with HLHS. Susceptibility to brain injury may depend on innate patient factors and may be influenced by surgical and preoperative and postoperative management strategies.

Hypoxic-ischemic lesions, similar to white matter injuries seen in preterm children, are common in neonates with HLHS before and after the Norwood procedure. ${ }^{11,18-20}$; however, previous studies evaluating the relationship between lesions on MRI and $\mathrm{ScO}_{2}$ reported inconsistent results. The risk of new or worsened ischemic lesions on postoperative cerebral MRI in patients undergoing the Norwood procedure was increased in patients with $\mathrm{ScO}_{2}<45 \%$ for more than 180 minutes in 1 study, ${ }^{11}$ whereas no association between 
white matter injury and postoperative $\mathrm{ScO}_{2}$ was found in 2 other studies. ${ }^{19,20}$ Ischemic lesions can be detected before Norwood surgery, indicating that preoperative hemodynamics might cause perioperative brain injury. In our patients, lower preoperative $\mathrm{ScO}_{2}$ value was significantly correlated with below-average IQ and KET-KID test scores. In agreement with our results, Lynch and colleagues ${ }^{20}$ reported that preoperative $\mathrm{ScO}_{2}$ values tended to be lower in patients with new or worsened periventricular white matter injury. They also reported that longer time to surgery was related to the extent of postoperative white matter injury. ${ }^{20}$

In our study, age at surgery was negatively correlated with IQ and KET-KID scores and tended to be higher in patients with poor neurodevelopmental outcomes. We also found a negative correlation between mean cerebral NIRS values 24 hours before surgery and age at surgery, suggesting that cerebral oxygenation deteriorates from birth until surgery. The difference between $\mathrm{SaO}_{2}$ and $\mathrm{ScO}_{2}$ served as an estimate of the cerebral arteriovenous saturation difference, reflecting the balance of oxygen supply and consumption. This value was higher in the preoperative period than in the later postoperative course. Therefore, the risk of impaired cerebral oxygenation also might be increased in the preoperative period, although absolute NIRS values were in a normal range for patients with HLHS and clearly above the suggested threshold of $40 \%$ to $45 \%$. Lynch and colleagues ${ }^{20}$ surmised that the brain's oxygen demand might not be well matched with the poor and possibly decreasing systemic oxygen delivery seen in patients with HLHS in the first days of life.

Although perioperative $\mathrm{ScO}_{2}$ was associated with neurodevelopmental outcomes in patients with HLHS and other congenital heart defects in previous studies, it was also influenced by additional factors, including age and weight at surgery, cardiopulmonary bypass and deep hypothermic circulatory arrest times, and length of intensive care unit or hospital stay. ${ }^{12,21-23}$ Patient-related factors, such as prematurity, birth weight, and the presence of a significant comorbidity, and parent education seem to be important determinants. ${ }^{21}$ In our cohort, younger gestational age was significantly associated with impaired neurodevelopmental outcomes. Prematurity, as well as late preterm and near-term delivery, have been previously identified as risk factors for neurodevelopmental impairment in patients with congenital heart defects. ${ }^{24}$

There is increasing evidence indicating that abnormal brain development starts in utero in children with congenital heart disease. Impaired brain growth and maturation have been reported in prenatal MRI studies. ${ }^{25,26}$ Head circumference $\mathrm{z}$-score at birth was significantly lower than population norms, and microcephaly was found in $14 \%$ of our patients, which might reflect smaller total brain volumes revealed by MRI studies in patients with HLHS. $^{26}$ Head circumference $z$-score and microcephaly were both associated with neurodevelopmental outcomes in our patients.

The present study has several important limitations. Even though our sample was larger than that in previous studies, our cohort of HLHS patients is still relatively small, and thus the generalizability of our results is limited. All patients underwent at least 2 additional surgical procedures before undergoing neurocognitive testing, and injury might have occurred during those procedures. Cerebral MRI was not performed in the perioperative course of the Norwood procedure, and no association between $\mathrm{ScO}_{2}$ and brain injury is apparent. Postoperative NIRS monitoring was analyzed for only 48 hours, but hemodynamic instability may occur during the later postoperative course as well. In this observational study, NIRS monitoring was not used for goal-directed therapy. There was no protocol for interventions when NIRS values were below certain thresholds.

In conclusion, cognitive and developmental outcomes in a contemporary cohort of preschool-age patients with HLHS was in the low-normal range, but $63 \%$ of the patients exhibited developmental delay in at least 1 neuropsychological domain. Our finding of an association between preoperative $\mathrm{ScO}_{2}$ and neurodevelopmental outcome warrants further investigation. Preoperative brain oxygenation might be inadequate even though cerebral NIRS values were above the accepted thresholds of $40 \%$ to $45 \%$. In contrast to surgical and postoperative variables, innate patient factors, particularly younger gestational age and smaller head circumference, were associated with impaired neurodevelopmental outcome. Altered intrauterine brain development in patients with HLHS may increase the susceptibility for perioperative injury.

\section{Conflict of Interest Statement}

Authors have nothing to disclose with regard to commercial support.

\section{References}

1. Tabbutt S, Nord AS, Jarvik GP, Bernbaum J, Wernovsky G, Gerdes M, et al. Neurodevelopmental outcomes after staged palliation for hypoplastic left heart syndrome. Pediatrics. 2008;121:476-83.

2. Newburger JW, Sleeper LA, Bellinger DC, Goldberg CS, Tabbutt S, Lu M, et al. Early developmental outcome in children with hypoplastic left heart syndrome and related anomalies: the single ventricle reconstruction trial. Circulation. 2012;125:2081-91

3. Sarajuuri A, Jokinen E, Mildh L, Tujulin AM, Mattila I, Valanne L, et al. Neurodevelopmental burden at age 5 years in patients with univentricular heart. Pediatrics. 2012;130:e1636-46.

4. Goldberg CS, Schwartz EM, Brunberg JA, Mosca RS, Bove EL, Schork MA et al. Neurodevelopmental outcome of patients after the fontan operation: a comparison between children with hypoplastic left heart syndrome and other functional single ventricle lesions. J Pediatr. 2000;137:646-52.

5. Mahle WT, Clancy RR, Moss EM, Gerdes M, Jobes DR, Wernovsky G. Neurodevelopmental outcome and lifestyle assessment in school-aged and 
adolescent children with hypoplastic left heart syndrome. Pediatrics. 2000;105: 1082-9.

6. Brosig C, Mussatto K, Hoffman G, Hoffmann RG, Dasgupta M, Tweddell J, et al. Neurodevelopmental outcomes for children with hypoplastic left heart syndrome at the age of 5 years. Pediatr Cardiol. 2013;34:1597-604.

7. Hirsch JC, Charpie JR, Ohye RG, Gurney JG. Near-infrared spectroscopy: what we know and what we need to know: a systematic review of the congenital heart disease literature. J Thorac Cardiovasc Surg. 2009;137:154-9.

8. Hoffman GM, Stuth EA, Jaquiss RD, Vanderwal PL, Staudt SR, Troshynski TJ, et al. Changes in cerebral and somatic oxygenation during stage 1 palliation of hypoplastic left heart syndrome using continuous regional cerebral perfusion. J Thorac Cardiovasc Surg. 2004; 127:223-33.

9. Uebing A, Furck AK, Hansen JH, Nufer E, Scheewe J, Dütschke P, et al. Perioperative cerebral and somatic oxygenation in neonates with hypoplastic left heart syndrome or transposition of the great arteries. J Thorac Cardiovasc Surg. 2011;142:523-30.

10. Phelps HM, Mahle WT, Kim D, Simsic JM, Kirshbom PM, Kanter KR, et al. Postoperative cerebral oxygenation in hypoplastic left heart syndrome after the Norwood procedure. Ann Thorac Surg. 2009;87:1490-4.

11. Dent CL, Spaeth JP, Jones BV, Schwartz SM, Glauser TA, Hallinan B, et al. Brain magnetic resonance imaging abnormalities after the Norwood procedure using regional cerebral perfusion. J Thorac Cardiovasc Surg. 2005;130:1523-30.

12. Hoffman GM, Brosig CL, Mussatto KA, Tweddell JS, Ghanayem NS. Perioperative cerebral oxygen saturation in neonates with hypoplastic left heart syndrome and childhood neurodevelopmental outcome. J Thorac Cardiovasc Surg. 2013;146:1153-64.

13. Voigt M, Fusch C, Olbertz D, Hartmann K, Rochow N, Renken C, et al. Analysis of the neonatal collective in the Federal Republic of Germany, 12th report: presentation of detailed percentiles for the body measurement of newborns. Geburtshilfe Frauenheilkd. 2006;66:956-70.

14. Stieh J, Fischer G, Scheewe J, Uebing A, Dütschke P, Jung O, et al. Impact of preoperative treatment strategies on the early perioperative outcome in neonates with hypoplastic left heart syndrome. J Thorac Cardiovasc Surg. 2006;131: 1122-9.e2.

15. Hansen JH, Petko C, Bauer G, Voges I, Kramer HH, Scheewe J. Fifteen-year single-center experience with the Norwood operation for complex lesions with single-ventricle physiology compared with hypoplastic left heart syndrome. $J$ Thorac Cardiovasc Surg. 2012;144:166-72.

16. Kurth CD, Levy WJ, McCann J. Near-infrared spectroscopy cerebral oxygen saturation thresholds for hypoxia-ischemia in piglets. J Cereb Blood Flow Metab. 2002;22:335-41.
17. Kurth CD, McCann JC, Wu J, Miles L, Loepke AW. Cerebral oxygen saturation-time threshold for hypoxic-ischemic injury in piglets. Anesth Analg. 2009;108:1268-77.

18. Goff DA, Shera DM, Tang S, Lavin NA, Durning SM, Nicolson SC, et al. Risk factors for preoperative periventricular leukomalacia in term neonates with hypoplastic left heart syndrome are patient related. J Thorac Cardiovasc Surg. 2014;147:1312-8.

19. Andropoulos DB, Hunter JV, Nelson DP, Stayer SA, Stark AR, McKenzie ED, et al. Brain immaturity is associated with brain injury before and after neonatal cardiac surgery with high-flow bypass and cerebral oxygenation monitoring. J Thorac Cardiovasc Surg. 2010;139:543-56.

20. Lynch JM, Buckley EM, Schwab PJ, McCarthy AL, Winters ME, Busch DR, et al. Time to surgery and preoperative cerebral hemodynamics predict postoperative white matter injury in neonates with hypoplastic left heart syndrome. J Thorac Cardiovasc Surg. 2014;148:2181-8.

21. Simons J, Sood ED, Derby CD, Pizarro C. Predictive value of near-infrared spectroscopy on neurodevelopmental outcome after surgery for congenital heart disease in infancy. J Thorac Cardiovasc Surg. 2012;143:118-25.

22. Sood ED, Benzaquen JS, Davies RR, Woodford E, Pizarro C. Predictive value of perioperative near-infrared spectroscopy for neurodevelopmental outcomes after cardiac surgery in infancy. J Thorac Cardiovasc Surg. 2013; 145:438-45.e1.

23. Kussman BD, Wypij D, Laussen PC, Soul JS, Bellinger DC, DiNardo JA, et al. Relationship of intraoperative cerebral oxygen saturation to neurodevelopmental outcome and brain magnetic resonance imaging at 1 year of age in infants undergoing biventricular repair. Circulation. 2010;122:245-54.

24. Goff DA, Luan X, Gerdes M, Bernbaum J, D'Agostino JA, Rychik J, et al. Younger gestational age is associated with worse neurodevelopmental outcomes after cardiac surgery in infancy. J Thorac Cardiovasc Surg. 2012; 143:535-42.

25. Limperopoulos C, Tworetzky W, McElhinney DB, Newburger JW, Brown DW, Robertson RL Jr, et al. Brain volume and metabolism in fetuses with congenital heart disease: evaluation with quantitative magnetic resonance imaging and spectroscopy. Circulation. 2010;121:26-33.

26. Licht DJ, Shera DM, Clancy RR, Wernovsky G, Montenegro LM, Nicolson SC, et al. Brain maturation is delayed in infants with complex congenital heart defects. J Thorac Cardiovasc Surg. 2009;137:529-36.

Key Words: hypoplastic left heart syndrome, developmental outcome, near-infrared spectroscopy 